\title{
The Dependence of Global Cloud and Lapse Rate Feedbacks on the Spatial Structure of Tropical Pacific Warming
}

\author{
TIMOTHY ANDREWS AND MARK J. WEBB \\ Met Office Hadley Centre, Exeter, United Kingdom
}

(Manuscript received 10 February 2017, in final form 29 September 2017)

\begin{abstract}
An atmospheric general circulation model (AGCM) is forced with patterns of observed sea surface temperature (SST) change and those output from atmosphere-ocean GCM (AOGCM) climate change simulations to demonstrate a strong dependence of climate feedback on the spatial structure of surface temperature change. Cloud and lapse rate feedbacks are found to vary the most, depending strongly on the pattern of tropical Pacific SST change. When warming is focused in the southeast tropical Pacific-a region of climatological subsidence and extensive marine low cloud cover-warming reduces the lower-tropospheric stability (LTS) and low cloud cover but is largely trapped under an inversion and hence has little remote effect. The net result is a relatively weak negative lapse rate feedback and a large positive cloud feedback. In contrast, when warming is weak in the southeast tropical Pacific and enhanced in the west tropical Pacific-a strong convective region-warming is efficiently transported throughout the free troposphere. The increased atmospheric stability results in a strong negative lapse rate feedback and increases the LTS in low cloud regions, resulting in a low cloud feedback of weak magnitude. These mechanisms help explain why climate feedback and sensitivity change on multidecadal time scales in AOGCM abrupt $4 \mathrm{xCO}_{2}$ simulations and are different from those seen in AGCM experiments forced with observed historical SST changes. From the physical understanding developed here, one should expect unusually negative radiative feedbacks and low effective climate sensitivities to be diagnosed from real-world variations in radiative fluxes and temperature over decades in which the eastern Pacific has lacked warming.
\end{abstract}

\section{Introduction}

Climate model simulations of surface temperature change in response to long-term greenhouse gas forcing show robust large-scale features: 1) larger warming generally occurs over land compared to the oceans, 2) warming is amplified at high latitudes, 3 ) minima in surface warming occur in the Southern Ocean, and 4) warming is "El Niño like" in the equatorial Pacific (Collins et al. 2013). Yet during historical climate change, the spatial structure of surface temperature change is complicated by different time-scale responses in the climate system (e.g., Held et al. 2010; Li et al. 2013), unforced variability on annual to multidecadal time scales (e.g., Kosaka and Xie 2013; Dai et al. 2015), and temporal and spatial variations in anthropogenic forcing (e.g., Booth et al. 2012; Boo et al. 2015; Smith et al. 2015). In particular, atmosphere-ocean general circulation models (AOGCMs) suggest that surface

Corresponding author: Timothy Andrews, timothy.andrews@ metoffice.gov.uk temperature change is initially delayed in the southeast tropical Pacific and Southern Ocean in response to forcing (e.g., Senior and Mitchell 2000; Held et al. 2010; Li et al. 2013; Andrews et al. 2015; Armour et al. 2016; Luo et al. 2017).

Varying with surface temperature change are feedback processes that directly alter Earth's energy budget. Wellestablished feedback processes are the Planck, lapse rate, water vapor, cloud, and sea ice/snow surface albedo feedbacks (e.g., Bony et al. 2006; Flato et al. 2013). There is an increasing realization that feedback processes are sensitive to the varying spatial structure of surface temperature change. This has been seen in both idealized GCM climate change simulations (e.g., Senior and Mitchell 2000; Williams et al. 2008; Andrews et al. 2012a; Geoffroy et al. 2013; Armour et al. 2013; Rose et al. 2014; Kang and Xie 2014; Andrews et al. 2015; Rugenstein et al. 2016) and GCMs forced by observed variations in sea surface temperatures (SSTs) and sea ice (Andrews 2014; Gregory and Andrews 2016; Zhou et al. 2016).

A dependence of radiative feedbacks on the spatial structure of surface temperature change may provide a 
mechanism to reconcile potential differences between historical energy budget estimates of climate sensitivity (which tend to be lower) and those simulated by AOGCMs forced by $\mathrm{CO}_{2}$ increases (which tend to be higher) (e.g., Armour 2016; Gregory and Andrews 2016; Forster 2016; Armour 2017). Similarly, it may explain why simulated cloud radiative feedbacks derived from interannual variations in top-of-the-atmosphere (TOA) radiative fluxes and surface temperature change, the pattern of which is dominated by El Niño-Southern Oscillation (ENSO), have been found to be different from those acting on long-term climate change (e.g., Dessler 2013; Zhou et al. 2015).

Despite strong modeling evidence for variation in climate sensitivity and feedback parameters, a robust physical understanding of why climate feedbacks depend on the spatial structure of surface temperature change is currently lacking. Identifying such a mechanism is a necessary first step in assessing the credibility of the GCM results. Andrews et al. (2015) showed that in abrupt $4 \mathrm{xCO}_{2}$ AOGCM simulations cloud feedbacks strengthen on multidecadal time scales, in part due to evolving patterns of east-west tropical Pacific SST changes, which likely alter lower-tropospheric stability (LTS) and low cloud cover (e.g., Williams et al. 2008; Qu et al. 2015a). Zhou et al. (2016) found substantial decadal variations in the strength of cloud feedbacks and Earth's energy budget when forcing their AGCM with historical SST variations. They attributed this to a dependence of tropical-mean low-level cloud change on lower-atmospheric stability and its relationship to surface warming in tropical ascent and descent regions (see also Zhou et al. 2017). Here we further develop and refine these mechanisms, extending them to a wider set of SST patterns and, like Senior and Mitchell (2000), identify changes in lapse rates as well as cloud feedbacks as being driven by a similar mechanism. We begin (section 2) by describing the experimental design and various changes in SST patterns that we use in this study. Section 3 proposes and tests a mechanism that relates the changes in SST patterns to variations in cloud and lapse rate feedbacks. Section 4 discusses the robustness of this mechanism and the implications for observed climate change.

\section{Surface warming patterns and radiative feedbacks}

\section{a. Approach and experimental design}

To investigate the dependence of radiative feedbacks on the pattern of surface temperature change we force the atmospheric component of the Hadley Centre Global Environmental Model, version 2 [HadGEM2-A; a detailed description of the model is provided by Martin et al. (2011)], with various patterns of SST change. HadGEM2 is a good choice of model for this investigation since its change in feedback strength under an abrupt quadrupling of $\mathrm{CO}_{2}$ is close to that of phase 5 of the Coupled Model Intercomparison Project (CMIP5) multimodel-mean change (Andrews et al. 2015); thus, the variation in feedback strength in HadGEM2 is not unusual in comparison to other contemporary models.

Our control experiment is identical to the CMIP5 amip experiment (Taylor et al. 2012); that is, we force HadGEM2-A with monthly observed SST and sea ice variations and all forcing agents (e.g., greenhouse gases, aerosols) for the 30-yr period 1979-2008. Note that GCMs forced in this way show good agreement with observed energy budget variations over a range of surface temperature anomalies and time scales (e.g., Allan et al. 2014; Smith et al. 2015). Our first two perturbation experiments are identical to the CMIP5 amip4k and amipFuture experiments (Bony et al. 2011), though we refer to these experiments with the updated terminology used in the Cloud Feedback Model Intercomparison Project (CFMIP) contribution to CMIP6 (amip-p4K and amip-future4K, respectively) (Webb et al. 2017). amip$\mathrm{p} 4 \mathrm{~K}$ is the same as the amip control experiment, except that the SSTs are subject to a uniform warming of $4 \mathrm{~K}$. amip-future $4 \mathrm{k}$ is also the same as the amip control experiment, except the SSTs are subject to a warming pattern derived from the multimodel ensemble mean response of AOGCMs forced by a $1 \% \mathrm{yr}^{-1} \mathrm{CO}_{2}$ increase [details are given in Webb et al. (2017)]. The perturbation is scaled such that the global-mean SST increase is $4 \mathrm{~K}$ relative to the amip control experiment. Note that in all perturbation experiments it is only the SSTs that are changed; the sea ice fraction is identical to the amip control experiment and so the sea ice fraction feedback is zero by construction.

In a similar way, we add three new SST perturbation experiments. First, amip-obs $4 \mathrm{~K}$ is the same as the amip control experiment, except the SSTs are subject to a warming pattern illustrative of observed twentiethcentury trends. The warming pattern is the linear trend in SST at each grid box over the period 1900-2012 (calculated from a linear fit to the annual-mean SST time series) from the amip boundary condition SST dataset (Taylor et al. 2000; Hurrell et al. 2008). Again, the pattern is first normalized and then scaled to ensure a global-mean SST increase of $4 \mathrm{~K}$ relative to the amip control experiment, as it is in amip-p4k and amipfuture $4 \mathrm{k}$. Note that there will be uncertainty in the observed pattern used here, which we do not address, but our purpose is to develop a process understanding of the dependence of climate feedbacks to different SST 


\section{(a) Suface warming pattern}
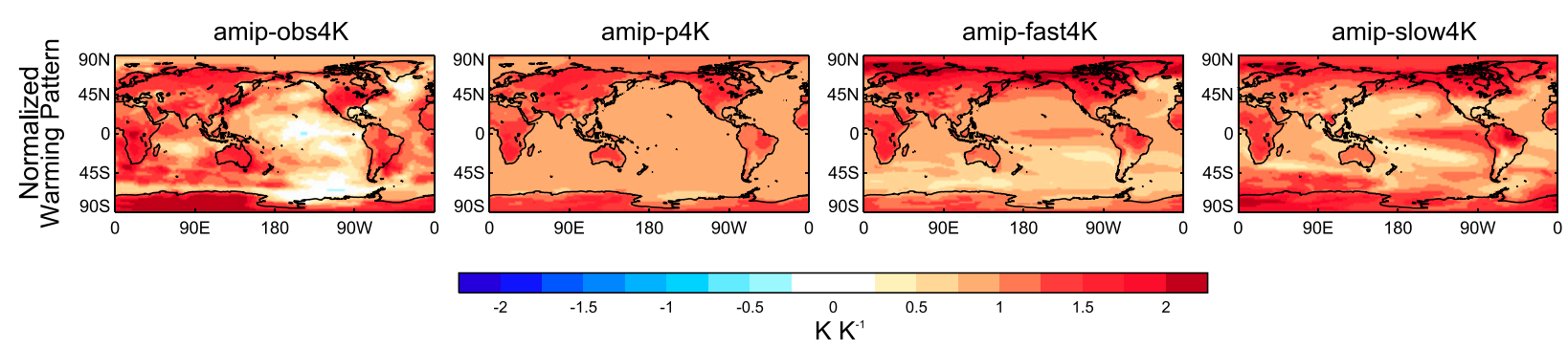

\section{(b) Radiative feedbacks}
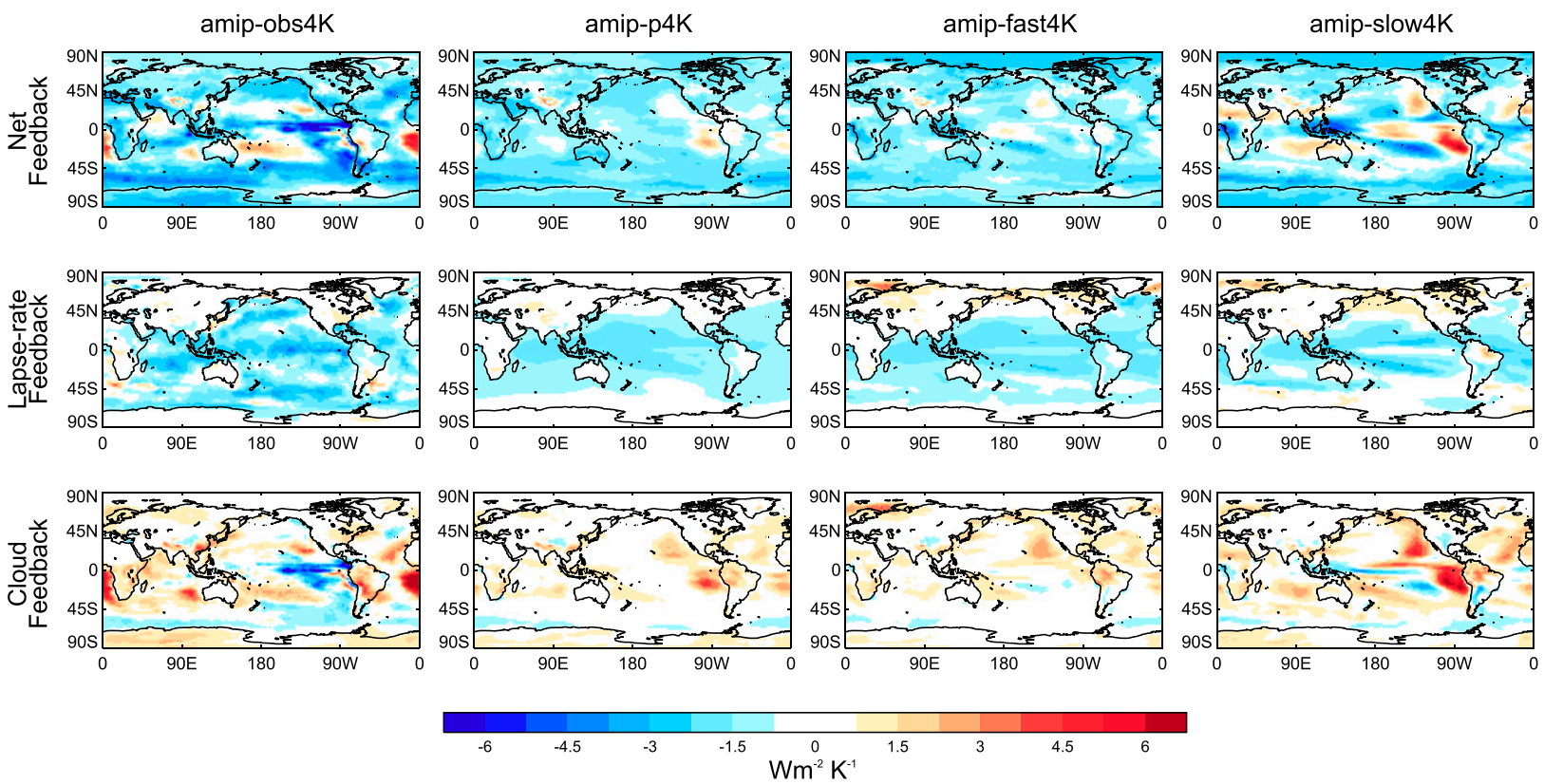

FIG. 1. (a) Change in near-surface air temperature $(1.5 \mathrm{~m}) \Delta T$, normalized by global-mean $\Delta T$, in the various amip- $4 \mathrm{~K}$ experiments (relative to the amip control). Note that over the oceans, $\Delta T$ closely follows the prescribed patterns of SST change. (b) The resulting net, lapse rate, and cloud radiative feedbacks to the SST perturbations.

patterns rather than to determine exactly what the pattern of twentieth-century SST change is. Second and third, amip-fast $4 \mathrm{k}$ and amip-slow $4 \mathrm{~K}$ are again the same as the amip control experiment, except this time the SSTs are subject to a warming pattern derived from the CMIP5 AOGCM-mean response to an abrupt quadrupling of $\mathrm{CO}_{2}$ averaged over years 1-20 (amip-fast4k) and years $21-150$ (amip-slow $4 \mathrm{~K}$ ) as derived and detailed in Andrews et al. (2015, their Fig. 5). Again, the patterns are normalized and then scaled to ensure a global-mean SST increase of $4 \mathrm{~K}$ relative to the amip control experiment. Note that all warming patterns are applied as a climatological annual mean, except for amip-future $4 \mathrm{k}$, which CFMIP provides as a monthly climatological warming pattern.

The pattern of $1.5-\mathrm{m}$ near-surface air temperature change (perturbation minus amip) for each experiment (except amip-future4k) is shown in Fig. 1a, and the key feature of each pattern is highlighted in Table 1. Note that the patterns of surface temperature change over land and sea ice must be a response to the SST perturbations. Since radiative forcings are unchanged between the control and perturbation experiments, the net feedback parameter $\alpha\left(\mathrm{W} \mathrm{m}^{-2} \mathrm{~K}^{-1}\right)$ can be derived simply from the change in net TOA radiative flux normalized by the global-mean near-surface air temperature change. The approach used is thus analogous to how feedback and sensitivity parameters have been routinely diagnosed and contrasted over many years, for example, initially using +2-K SST experiments (e.g., Cess et al. 1996), and more recently using amip $+4-\mathrm{K}$ SST experiments (Bony et al. 2011; Webb et al. 2017). The Planck, cloud, lapse rate, water vapor, and surface albedo feedbacks are isolated using the standard 
TABLE 1. Description of the SST perturbation experiments and key features of the surface warming pattern. All experiments are identical to the control amip experiment (i.e., an atmospheric GCM forced with monthly observed SST and sea ice variations and all forcing agents for the 30-yr period 1979-2008) except that in each case the SSTs are subject to the addition of the described warming pattern, each of which are scaled to ensure a global-mean SST increase of $4 \mathrm{~K}$ relative to the amip control experiment. Note that in all perturbation experiments the forcing agents and sea ice fraction boundary conditions are unchanged; it is only the SSTs that are perturbed.

\begin{tabular}{|c|c|c|}
\hline Experiment & Warming pattern & Key feature \\
\hline amip-obs4K & 1900-2012 linear trend of observed SSTs & Lack of warming in east Pacific \\
\hline amip-p4K & Uniform warming of $+4 \mathrm{~K}$ & Uniform warming \\
\hline amip-future $4 \mathrm{~K}$ & End of $1 \% \mathrm{CO}_{2}$ simulation & $\begin{array}{l}\text { Relatively small warming in the southeast tropical } \\
\text { Pacific and Southern Ocean }\end{array}$ \\
\hline amip-fast $4 \mathrm{~K}$ & First 20 years of abrupt $4 \mathrm{xCO}_{2}$ simulation & $\begin{array}{l}\text { Relatively small warming in the southeast tropical } \\
\text { Pacific and Southern Ocean }\end{array}$ \\
\hline amip-slow $4 \mathrm{~K}$ & Years $21-150$ of abrupt $4 \mathrm{xCO}_{2}$ simulation & $\begin{array}{l}\text { Relatively large warming in the east Pacific, Southern } \\
\text { Ocean, and high latitudes }\end{array}$ \\
\hline
\end{tabular}

radiative kernel technique of Soden et al. (2008), applied to monthly mean data. All results are means over the 30 -yr simulations.

\section{b. Radiative feedbacks}

The global-mean radiative feedbacks are shown in Table 2 and vary substantially depending on the SST pattern applied. The net feedback parameter ranges from $-0.98 \mathrm{~W} \mathrm{~m}^{-2} \mathrm{~K}^{-1}$ when we force HadGEM2-A with a pattern of SST change from the later part of abrupt $4 \mathrm{xCO}_{2}$ (amip-slow4K) to $-1.61 \mathrm{~W} \mathrm{~m}^{-2} \mathrm{~K}^{-1}$ when the model is forced with observed twentieth-century SST trends (amip-obs $4 \mathrm{~K}$ ). This translates to a range of effective climate sensitivity (EffCS $=-F_{2 x} / \alpha$; i.e., the equilibrium response to a doubling of $\mathrm{CO}_{2}$ assuming a constant feedback parameter $\alpha)^{1}$ from $\sim 5$ to $2.6 \mathrm{~K}$, respectively. Note that the model physics is unchanged between these simulations; the change in sensitivity occurs purely due to the different pattern of SST change applied to the model.

When forced with the initial warming pattern of abrupt4xCO2 (amip-fast4k) the feedback parameter is more negative (effective climate sensitivity smaller) than in the amip-slow4K experiment. This implies that the effective climate sensitivity should increase after $20 \mathrm{yr}$ in abrupt $4 \mathrm{xCO} 2$ owing to the change in warming pattern, recovering the results of Andrews et al. (2015) and Geoffroy et al. (2013) (among others) but using a different methodology.

The surface albedo feedback is small but positive owing to the melting of snow cover over land (recall that the sea ice feedback is excluded by design) and largely

\footnotetext{
${ }^{1}$ In this calculation we assume the multimodel-mean effective radiative forcing of $3.4 \mathrm{~W} \mathrm{~m}^{-2}$ for a doubling of $\mathrm{CO}_{2}\left(F_{2 x}\right)$ (Forster et al. 2013) and a typical surface albedo feedback of $+0.3 \mathrm{~W} \mathrm{~m}^{-2} \mathrm{~K}^{-1}$ (Flato et al. 2013) (which is added to $\alpha$ ).
}

independent of the warming pattern. The global-mean Planck feedback is also largely independent of the warming pattern, even though this cannot be the case regionally since the Planck feedback is the product of the temperature kernel and the normalized warming pattern (e.g., Feldl and Roe 2013). Cloud and lapse rate feedbacks show the largest dependence on the surface temperature pattern, ranging from +0.40 to $+0.60 \mathrm{~W} \mathrm{~m}^{-2} \mathrm{~K}^{-1}$ and from -1.06 to $-0.58 \mathrm{~W} \mathrm{~m}^{-2} \mathrm{~K}^{-1}$ in amip-slow4K and amip-obs $4 \mathrm{~K}$, respectively. Some of the spread in lapse rate feedback is anticorrelated with the variation in the water vapor feedback-a wellknown result commonly seen across GCM feedbacks (e.g., Soden and Held 2006). Cloud and lapse rate feedbacks vary significantly and explain most of the variation in the net feedback across the experiments (both have correlation coefficients $r$ with net feedback greater than 0.9) and are strongly correlated with each other $(r=0.9)$. This suggests a common mechanism between cloud and lapse rate variations, which is the focus of the rest of this study.

Note that the residual (net feedback minus sum of individual feedbacks as determined from the radiative kernels) is not negligible, as also seen in other studies that use radiative kernel techniques (e.g., Vial et al. 2013), and can be interpreted as a nonlinear term (e.g., Feldl and Roe 2013). In addition, HadGEM2 has a mineral dust scheme that has been shown to give rise to changes in atmospheric dust load and top-of-theatmosphere radiation under climate change (e.g., Andrews et al. 2012b), which would be aliased into the residual here. Regardless, the residual is mostly robust to the warming pattern (Table 2), even at regional scales (not shown). We further believe that it has no bearing on our conclusions that cloud and lapse rate feedbacks show significant dependence on the pattern of warming since 1) the feedback differences across different warming patterns are consistent with changes in physical 
TABLE 2. Radiative feedbacks $\left(\mathrm{W} \mathrm{m}^{-2} \mathrm{~K}^{-1}\right.$ ) derived from the various amip-4K experiments. The Planck, lapse rate (LR), water vapor (WV), surface albedo, and cloud feedbacks are isolated using the standard radiative kernel technique of Soden et al. (2008), applied to monthly mean data. Results are means over the 30-yr simulations. The residual is the difference between the net feedback (change in TOA radiative flux normalized by global-mean near-surface air temperature change) and the sum of individual feedbacks as determined from the radiative kernel technique.

\begin{tabular}{lcccccccc}
\hline \hline Experiment & Net & Planck & LR & WV & WV + LR & Albedo & Cloud & Residual \\
\hline amip-obs4K & -1.61 & -3.20 & -1.06 & 1.82 & 0.76 & 0.08 & 0.40 & 0.35 \\
amip-p4k & -1.31 & -3.19 & -0.85 & 1.75 & 0.9 & 0.09 & 0.49 \\
amip-future4k & -1.37 & -3.22 & -1.01 & 1.88 & 0.87 & 0.09 & 0.45 & 0.40 \\
amip-fast4k & -1.31 & -3.18 & -0.81 & 1.76 & 0.95 & 0.10 & 0.44 \\
amip-slow4K & -0.98 & -3.16 & -0.58 & 1.64 & 1.06 & 0.09 & 0.60 \\
\hline
\end{tabular}

processes (e.g., differences in cloud and atmospheric temperature responses to different warming patterns; see next paragraph and section 3) and 2) calculating the feedbacks simply from changes in radiative fluxes without kernels (e.g., longwave clear-sky or cloud radiative effects) provides consistent results (not shown).

The variation in cloud feedback is dominated by regions of marine stratocumulus in the southeast tropical Pacific (Fig. 1b, bottom). There exists a strong positive cloud feedback associated with a reduction in low clouds in the amip-slow4K experiment; this is weaker in amip$\mathrm{p} 4 \mathrm{k}$ and amip-fast $4 \mathrm{k}$ and even changes sign in amipobs4K. This is also the dominant feature seen in the variation of the net feedback parameter (Fig. 1b, top). The spread in lapse rate feedback is also large in the tropical Pacific but also shows variations at mid- and high latitudes too, where it is strong and negative in amip-obs4K but weak in amip-slow4K (Fig. 1b, middle). This is clearly illustrated in Fig. 2a, which shows the zonal-mean profile of the deviation from vertically uniform warming [i.e., $\Delta T(z)-\Delta T_{\text {surface, }}$, where $\Delta T(z)$ is the change in air temperature at height $z$ and $\Delta T_{\text {surface }}$ the surface temperature change], normalized by the global-mean near-surface air temperature change. The product of this deviation from vertically uniform warming with the temperature kernel gives the lapse rate feedback (Fig. 2b). In all experiments the lapse rate feedback is strongly negative in the upper tropical troposphere but also at midlatitudes over the Southern Ocean in amip-obs4K. In contrast, the lapse rate changes and lapse rate feedbacks are largely restricted to the upper tropical troposphere in amip-slow4K, relative to the other patterns, and lack the changes at midlatitudes.

Our key finding is that in amip-slow4K, where HadGEM2-A is forced with a pattern of surface temperature change taken from the latter part of the CMIP5 AOGCM abrupt $4 \mathrm{xCO}_{2}$ simulation (which has relatively strong southeast tropical Pacific and Southern Ocean warming), it simulates a relatively strong positive cloud feedback in the southeast tropical Pacific and a relatively weak negative lapse rate feedback. Together these give a globally less negative feedback parameter and large effective climate sensitivity. In contrast, when HadGEM2A is forced with a pattern of surface temperature change derived from observed historical climate change (amipobs4K) (which has relatively weak warming in the east Pacific), it simulates a relatively weak (or even negative) cloud feedback in the east tropical Pacific and a relatively strong negative lapse rate feedback. Together, these give a strongly negative feedback parameter and small effective climate sensitivity. The other warming patterns and feedback results largely fall between these extremes. In the next section we propose a mechanism to explain these dependencies.

\section{Mechanism}

\section{a. East-west tropical Pacific warming mechanism}

We propose a simple mechanism that relates cloud and temperature lapse rate changes in the tropical Pacific. First, note that marine low cloud changes are well described by reductions in low cloud fraction in response to local SST increases (e.g., Rieck et al. 2012; Webb and Lock 2013; Qu et al. 2014; Brient et al. 2016; Bretherton 2015) and increases in low cloud fraction in response to increases in lower-tropospheric stability (LTS $=\theta_{700 \mathrm{hPa}}-\theta_{\text {srf }}$ ) (e.g., Klein and Hartmann 1993; Qu et al. 2014, 2015b), where $\theta_{700 \mathrm{hPa}}$ and $\theta_{\text {srf }}$ are the potential temperatures at $700 \mathrm{hPa}$ and the surface, respectively. This suggests that low cloud changes depend on local SST changes and remote effects that influence free tropospheric temperatures and hence lower-tropospheric stability. Second, since warming in the free troposphere is relatively horizontally uniform, variations in lapse rate feedback are also determined by the structure of surface temperature change

\footnotetext{
${ }^{2} \mathrm{Qu}$ et al. (2014, 2015b) actually use the estimated inversion strength (EIS) of Wood and Bretherton (2006) rather than LTS, but EIS and LTS have a similar characteristic response (Webb et al. 2013).
} 
(a) Deviation from vertically uniform temperature change $\left(\Delta T(z)-\Delta T_{\text {surface }}\right)$
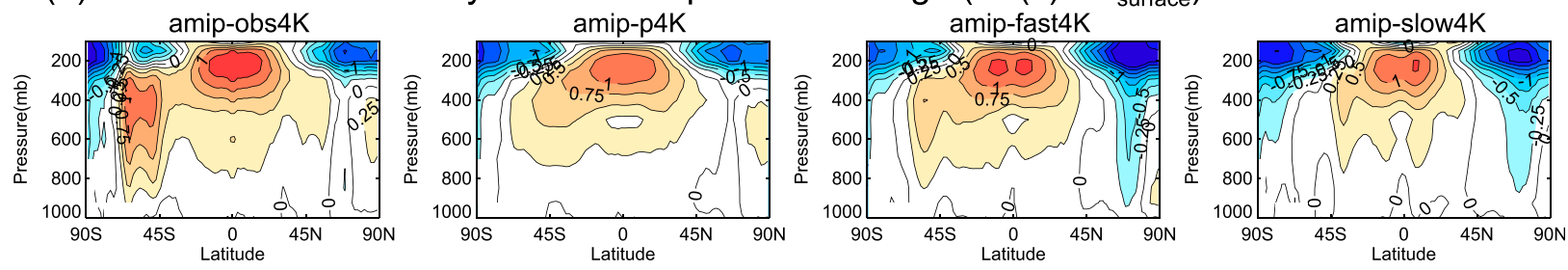

(b) Lapse-rate feedback
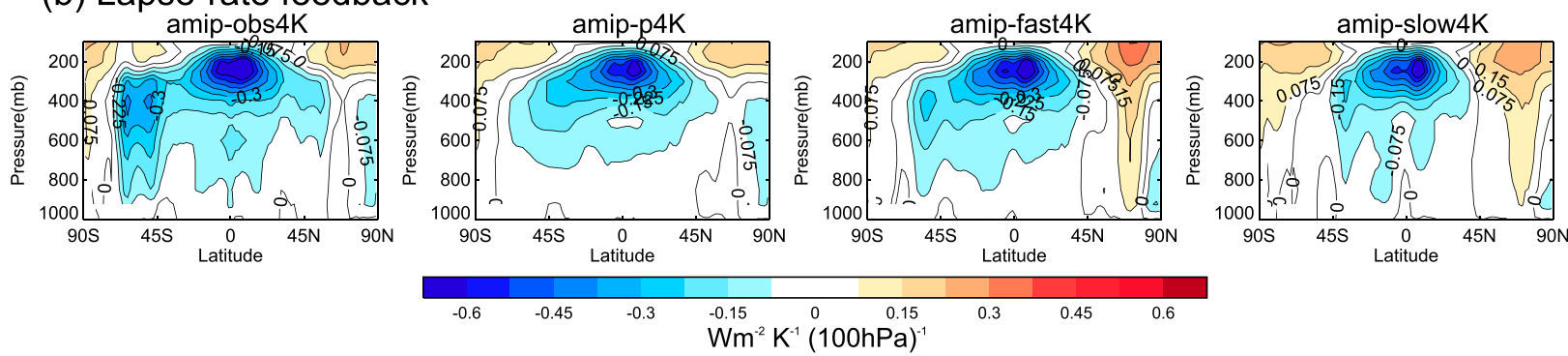

FIG. 2. (a) Zonal-mean profiles of the deviation from vertically uniform warming [defined as the change in $T(z)-T$ surface, where $T(z)$ is the air temperature at height $z$, and $T_{\text {surface }}$ is the surface temperature], normalized by global-mean near-surface air temperature change, due to the various amip-4K SST perturbations. (b) The resulting lapse rate feedbacks in each experiment, which are the product of (a) and the temperature kernel.

(Po-Chedley and Fu 2012; Flannaghan et al. 2014; Lambert and Taylor 2014; Ferraro et al. 2015).

Now imagine and contrast two idealized warming scenarios, one where warming is focused in regions of strong subsidence and low cloudiness, such as the southeast tropical Pacific, and one where warming is focused in regions of strong convection, such as the west Pacific warm pool. Note that these are extreme scenarios and in practice temperature change occurs in both with various amplitudes. In the first scenario, if tropical warming was focused in the low cloud regions of the southeast tropical Pacific then warming would be largely trapped under the inversion that caps the boundary layer (Zhou et al. 2016, 2017). This would result in a large positive cloud feedback to the local surface warming but also a significantly reduced LTS since there is little temperature change above the cloud layer in the free troposphere at $700 \mathrm{hPa}$; that is, $d \theta_{700 \mathrm{hPa}} \sim 0$, and hence $d$ LTS $\sim-d \theta_{\text {srf }}$. A reduced LTS entrains warm and dry air from above, further reducing the low cloud cover and resulting in an even larger cloud feedback (e.g., Bretherton 2015). In addition, since the warming is inefficiently transported to upper levels, the result is a weak lapse rate feedback. Hence in this scenario cloud feedback is large and positive, while the negative lapse rate feedback is weak, and so the effective climate sensitivity is large.

In contrast, in the second scenario, if warming was focused in the strong convective regions of the west Pacific and weak in the southeast tropical Pacific, then warming would be efficiently transported to upper levels and throughout the free troposphere. The result would be a strong warming aloft, increasing stability and the atmospheric lapse rate feedback (e.g., Po-Chedley and Fu 2012; Flannaghan et al. 2014). Furthermore, the free tropospheric warming increases LTS in the low cloud regions, which throttles (or can even offset) the positive low cloud feedback from local SST changes (e.g., Qu et al. 2015b; Zhou et al. 2016, 2017), which was already weak owing to the relatively weak warming in these regions. Hence in this scenario cloud feedback is small or negative, while the negative lapse rate feedback is strong, and so the effective climate sensitivity is small.

\section{b. Can this mechanism explain the variation in feedbacks?}

We test whether such a mechanism is able to explain the variation in feedbacks seen in our experiments by creating a simple index that contrasts the normalized warming pattern averaged over two key approximately equal area tropical regions of strong ascent and descent: the west Pacific $\left(15^{\circ} \mathrm{S}-15^{\circ} \mathrm{N}, 150^{\circ}-170^{\circ} \mathrm{E}\right)$ and the southeast tropical Pacific $\left(30^{\circ} \mathrm{S}-0^{\circ}, 260^{\circ}-280^{\circ} \mathrm{E}\right)$, respectively (see boxes in Fig. $5 \mathrm{c}$ below). Defined as southeast minus west Pacific $\Delta T$ (here $\Delta T$ is the nearsurface air temperature change normalized by the global-mean change), when this index is $>0$ it indicates relatively larger warming in the southeast Pacific (such as in amip-slow4K) per unit of global temperature 
(a) Net Feedback

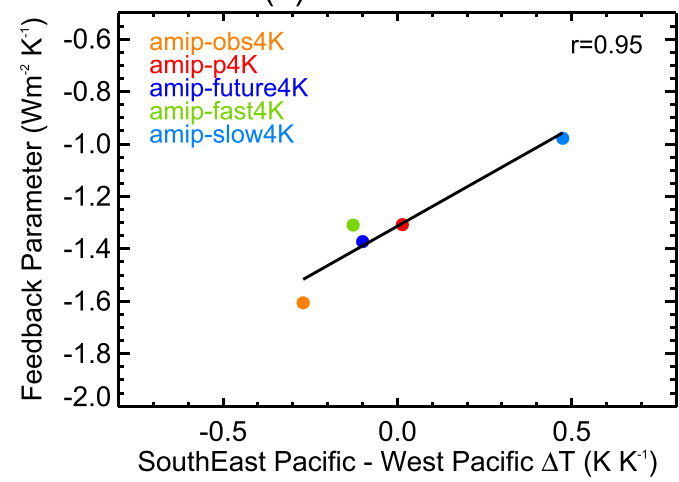

(b) Cloud \& Lapse-rate Feedbacks

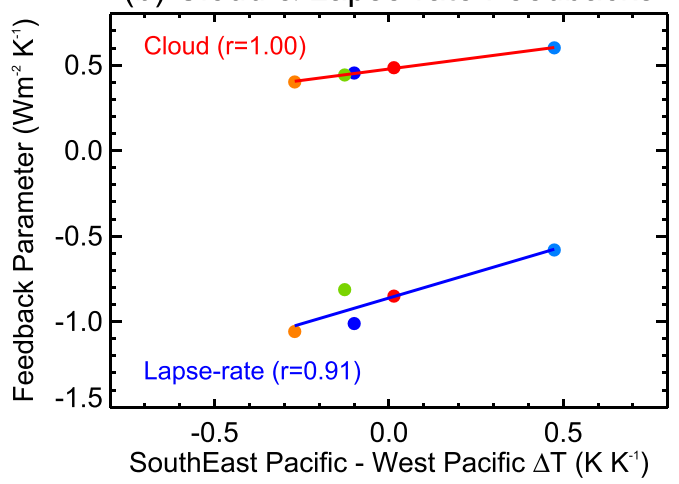

FIG. 3. Relationship between a tropical Pacific warming pattern index, defined as the difference between the normalized southeast and west tropical Pacific warming patterns (see section 3b) and the global-mean (a) net feedback and (b) cloud and lapse rate feedbacks.

change. Consequently according to the mechanism of Section 3a we would expect a larger fraction of warming to be trapped in the boundary layer, reducing low cloud cover (large positive cloud feedback) and a smaller lapse rate change (weak negative lapse rate feedback). In contrast, when the index $<0$ it suggests relatively greater warming in the west Pacific than in the east (such as in amip-obs4K). Consequently we would expect a smaller low cloud change (or a change in sign) and a larger warming of the free troposphere, increasing the lapse rate and LTS of low cloud regions.

Figure 3 shows that such an index is extremely well correlated with the global-mean net $(r=0.95)$, lapse rate $(r=0.91)$, and cloud $(r=1.00)$ feedback variation across the various patterns of surface temperature change. The index is able to explain over $80 \%$ of the variance for each variable. Correlating the lapse rate and cloud feedbacks against 1) solely the southeast tropical Pacific average (divided by global $\Delta T$ ) gives $r=0.82$ and $r=0.93$, respectively, and 2) solely the west Pacific average gives $r=-0.49$ and $r=-0.48$ respectively. Thus while the southeast Pacific index by itself is a reasonably good predictor of the global-feedback variation, it is the difference between the east and west tropical Pacific SST patterns that explains the most variance.

The correlation to the cloud feedback is remarkable (Fig. 3b). The boundaries of the regions used in the index were not chosen to maximize this correlation through trial and error, they were simply chosen to contrast the key regions of tropical Pacific subsidence (see Fig. 5c) and, in the case of the southeast tropical Pacific, a regime of marine low clouds, which are the basis for the targeted experiments and physical understanding developed in Sections 3c and 3d. Still, we test the sensitivity of all three correlations in Fig. 3 to the boundaries of the regions by expanding and shifting the regions. The correlations remain at or above 0.9 if the regions are extended $20^{\circ}$ east and west, or $20^{\circ}$ north and south. Similarly, shifting the regions $20^{\circ}$ north, south, or west also gives correlations at or above 0.9. If however, the regions are shifted beyond the large-scale east-west Pacific SST differences, for example $20^{\circ}$ eastward (which shifts the southeast tropical Pacific box over the South American continent), then no significant correlation is found ( $r=-0.03$ and $r=-0.13$ for the cloud and lapse rate feedback, respectively). Similarly, shifting the regions too far westward, for example a $90^{\circ}$ shift westward, gives correlations of only 0.2 . Hence the correlations of Fig. 3 are largely robust to the precise size/position of the regions used in the index, provided they capture the large-scale differences in east-west Pacific SST patterns.

We caution that this index is not general enough to explain the variation that might occur under any pattern of SST change, such as modes of climate variability like the Pacific decadal oscillation (PDO) (e.g., Newman et al. 2016). For example, a large positive value could occur from either large warming in the east tropical Pacific and none in the west, or a very large warming in the east Pacific and some in the west. It is not clear that we should expect these to give the same feedbacks. In addition, we have focused only on one region of tropical descent and marine low clouds, but other regions may be important under different patterns of SST change (e.g., different ocean basins or the high latitudes; see the discussion in Section 4). Still, these results point to a strong dependence of cloud and lapse rate feedbacks on the spatial structure of tropical Pacific warming.

\section{c. Illustrating the mechanism in the southeast tropical Pacific}

To illustrate the mechanism in more detail we focus on the southeast tropical Pacific. Here low clouds are 
(a) Cloud Fraction

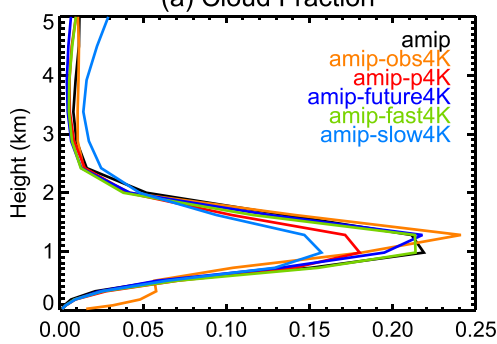

(d) $\Delta\left(\theta(\mathrm{z})-\theta_{\text {sff }}\right)(\mathrm{K})$

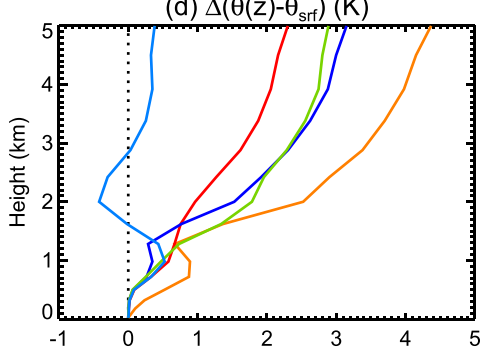

(b) Temperature $(\mathrm{K})$

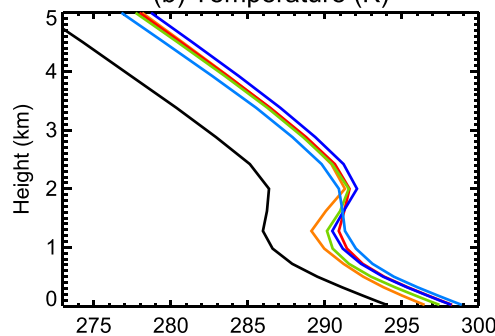

(e) Change in Low Cloud v $\Delta$ LTS

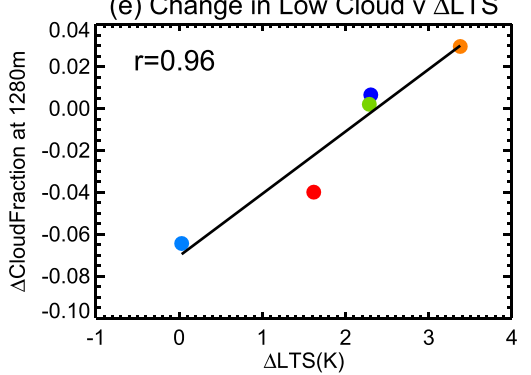

(c) Change in Temperature (K)

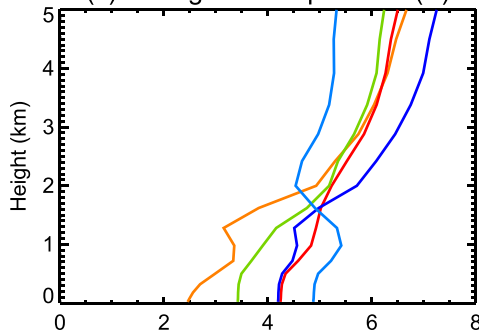

(f) Correlation of stability change $v \Delta$ LowCloud

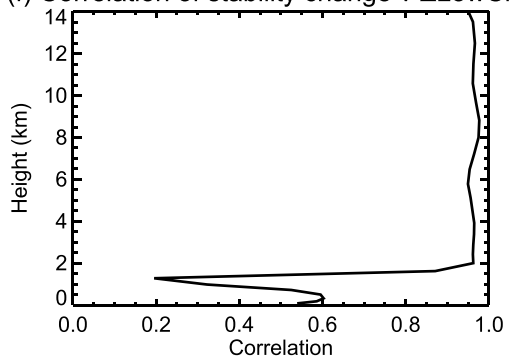

FIG. 4. Profiles averaged over the southeast tropical Pacific $\left(30^{\circ} \mathrm{S}-0^{\circ}, 260^{\circ}-280^{\circ} \mathrm{E}\right)$ of (a) cloud fraction, (b) temperature, (c) change in temperature, and (d) change in stability $\left[\theta(z)-\theta_{\text {srf }}\right.$. (e) Relationship between the change in low cloud fraction and change in LTS (f) Profile of the correlation between the change in stability at height $z$ in (d) against the change in low cloud cover in (a) at $1280 \mathrm{~m}$.

at a maximum at a height of $\sim 1-1.5 \mathrm{~km}$ (Fig. 4a) and sit under a temperature inversion that caps the boundary layer (Fig. 4b). Of all the surface warming patterns, amip-slow4K warms the most near the surface in this region, yet the least above the boundary layer (Fig. 4c). The result is a relatively uniform warming profile and little change in LTS (Figs. 4d,e). The change in LTS across warming patterns correlates strongly with the change in low cloud cover (Fig. 4e). In the example of amip-slow4K, the lack of LTS change gives the biggest reduction in low cloud cover (Fig. 4e), since there is little to no LTS-driven cloud changes to offset the large cloud response to the surface warming. The observed pattern of temperature change (amip-obs $4 \mathrm{~K}$ ) warms the least at the surface in this region, but above the inversion is more similar to the other experiments (Fig. 4c) due to remote warming of the free troposphere. Hence the change in lower-tropospheric stability (Figs. 4d,e) is by far the greatest in this experiment, inhibiting the mixing of warmer and drier air from above, to the extent that it offsets the local thermodynamic cloud feedback, and there is actually a slight increase in low cloud fraction (Figs. 4a,e) and a negative cloud feedback (Fig. 1b).

To establish a connection between stability changes throughout the column (which sets the lapse rate feedback) and low cloud feedback, Fig. 4f shows the correlation between the change in low cloud amount (defined by the level of maximum low clouds at $1280 \mathrm{~m}$ in Fig. 4a) and the stability change $\left[\Delta \theta(z)-\Delta \theta_{\text {srf }}\right]$ at height $z$. Above the inversion, the correlation between the change in atmospheric stability and low cloud remains, even up to $14 \mathrm{~km}$. Hence the variation in lapse rate and low cloud feedbacks are related through the common mechanism of changes in column atmospheric stability, not just LTS changes.

\section{d. Testing the mechanism with $+4 K$ patch experiments}

To test the mechanism and proposed physical processes further we perform two warming patch experiments where the SSTs are increased by $4 \mathrm{~K}$ in the west or southeast tropical Pacific only (Fig. 5a). These experiments are like the 30-yr amip-p4k experiment except the $4 \mathrm{~K}$ increase is constrained to the regions of the boxes. Note that these experiments are not used for feedback calculations since the global-mean surface temperature change is small. ${ }^{3}$

When the west Pacific SSTs are increased, the results confirm that warming is efficiently transported globally at upper levels in the tropics and to the midlatitudes (Fig. 5a), helping to explain why those warming patterns that favored the west Pacific have strong lapse rate feedbacks, even to the midlatitudes and particularly over the Southern Ocean (Fig. 1b, middle; Fig. 2). Figure 5a also confirms that warming in the west Pacific

\footnotetext{
${ }^{3}$ See Zhou et al. (2017) for a Green's function approach to using patch experiments more widely for feedback analysis.
} 
(a) Temperature and stability change to $+4 \mathrm{~K}$ patches
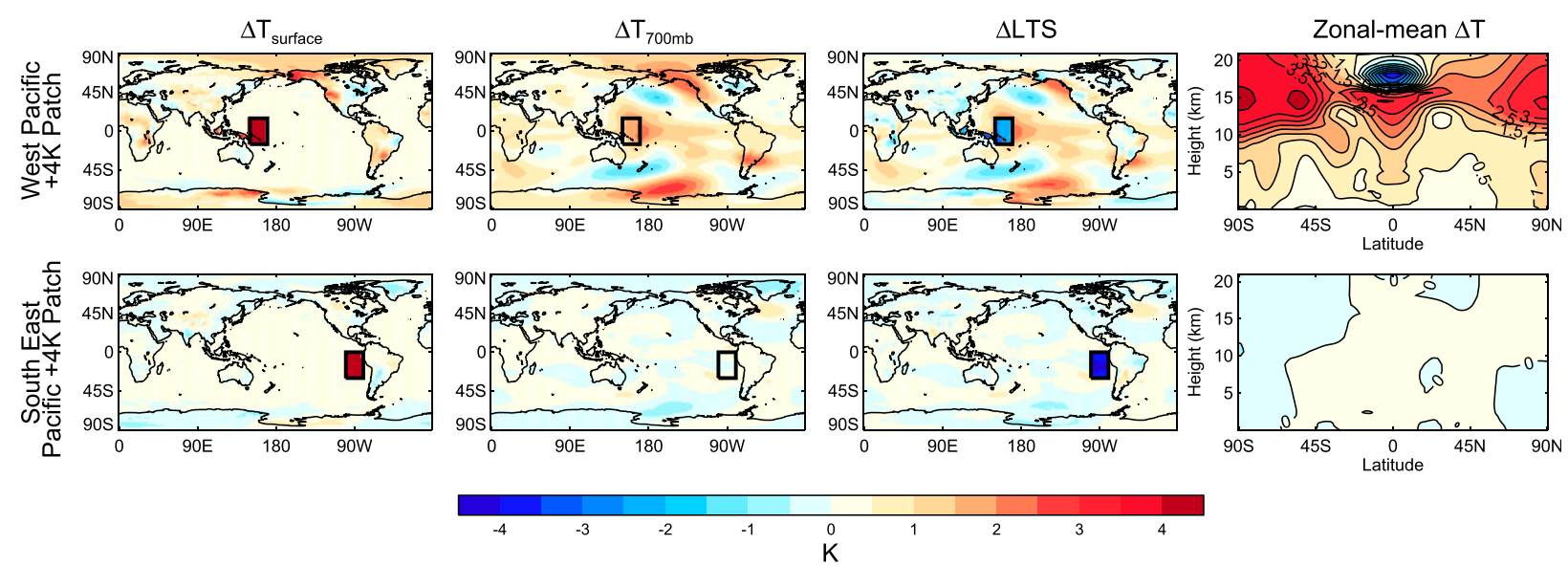

(b) Dynamical response to $+4 \mathrm{~K}$ west Pacific patch
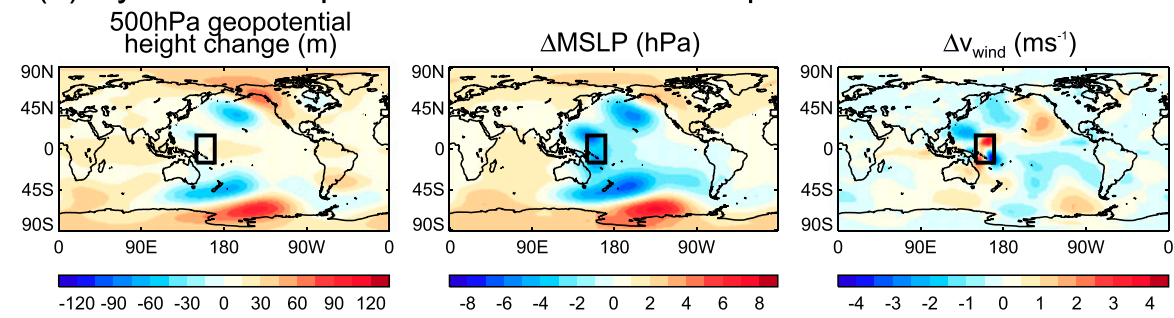

(c) Climatology

FIG. 5. (a) Change in surface temperature, 700-hPa temperature, LTS, and the zonal-mean temperature profile, for a $+4-\mathrm{K}$ warming in the (top) west Pacific and (bottom) southeast Pacific, as outlined by a black rectangle. (b) Dynamical responses to the $+4-\mathrm{K}$ west Pacific patch, including change in 500-hPa geopotential height, MSLP, and northerly wind $v_{\text {wind }}$ (c) Climatological subsidence at $500 \mathrm{hPa}$ in the amip control experiment, with black rectangles indicating the regions we define as west Pacific and southeast Pacific.

ascent region causes a reduction in LTS locally but large increases remotely, particularly in the tropics. In contrast, when the southeast Pacific is warmed there is virtually no warming seen throughout the atmosphere or even locally at $700 \mathrm{hPa}$. The change in LTS shows a strong reduction over the southeast Pacific where the local SST warming is applied but little remote effects, confirming that warming in the southeast tropical Pacific descent region is largely trapped under the inversion.

The remote tropical effects of warming in the west Pacific ascent region are consistent with a Gill-type dynamical response (Gill 1980). At midlatitudes, west Pacific warming results in cooling at $700 \mathrm{hPa}$ in parts of the Pacific (Fig. 5a). This is the result of a poleward propagating Rossby wave into both hemispheres that tends toward the east (e.g., Scaife et al. 2016). This is clearly illustrated by the dipole pattern seen in the change in $500 \mathrm{hPa}$ geopotential height and reflected in the change in mean surface level pressure (MSLP) (Fig. 5b). In the North Pacific, the reduction in MSLP increases cyclonic rotation (anticlockwise in the Northern Hemisphere), which leads to an increase in northerly $v$ winds on its eastern side and reduction on its western side (Fig. 5b). Consequently warm air is drawn up from the south on the eastern side of the North Pacific, and cold air is pulled down from the north on the western side. An analogous mechanism occurs in the Southern Hemisphere. These mechanisms are usually studied in the context of global teleconnections associated with modes of Pacific variability like ENSO and the PDO (e.g., Scaife et al. 2016). Here we suggest analogous mechanisms are at work in response to externally forced SST patterns, and these help explain in part the global-scale atmospheric temperature change patterns and feedbacks that arise from enhanced warming in the west Pacific. We do not pursue this further here, but there would be value in future work studying the dynamical changes associated with different patterns of SST change and how it relates to changes in temperature, clouds, and other climate feedbacks.

\section{Summary and discussion}

The spatial structure of surface temperature change is not constant, owing to spatiotemporal variations in 
anthropogenic forcing, intrinsic time scales of the response of the climate system, and internally generated coupled atmosphere-ocean variability on various time scales. Using HadGEM2-A forced with patterns of observed and simulated sea surface temperature change we have demonstrated a strong dependence of climate feedback on these variations in surface temperature change patterns. In particular cloud and lapse rate feedbacks are found to vary significantly according to patterns of tropical Pacific warming. When warming is focused in the southeast tropical Pacific, the warming reduces the regional lower-tropospheric stability and low cloud cover but is largely trapped under an inversion and hence has little remote effect. The net result is a relatively weak negative lapse rate feedback and a large positive cloud feedback. In contrast, when warming is weak in the southeast tropical Pacific and enhanced in the west tropical Pacific, the warming is efficiently transported throughout the tropical free troposphere and to the midlatitudes. The increased atmospheric stability results in a strong negative lapse rate feedback and dampens the lower-tropospheric stability change in the low cloud regions, resulting in a weak (or even a sign change) low cloud cover change and less positive cloud feedback.

These results reinforce the findings of Zhou et al. (2016, 2017), who found a dependence of tropical-mean low-cloud changes on the contrast between warming in tropical ascent and descent regions using the Community Earth System Model [CESM1.2.1 (CAM5.3)]. We have identified a similar mechanism in operation in HadGEM2-A, but using a different methodology and experimental design. We have additionally assessed the dependence of climate feedbacks beyond that of clouds on the structure of SST change. Lapse rate changes were found to be substantially bigger than cloud feedback changes in some cases (e.g., comparing amip-obs $4 \mathrm{~K}$ to amip-slow4K), although some of this variation is anticorrelated with water vapor feedback changes. Andrews et al. (2015) showed that longwave clear-sky feedback processes (which will be dominated by the Planck, lapse rate, and water vapor feedbacks) robustly became less negative in CMIP5 AOGCM abrupt $4 \mathrm{xCO}_{2}$ experiments but did not attribute this change to a particular process. Contrasting feedbacks in the amip-fast $4 \mathrm{k}$ and amipslow4K experiments (which have patterns of SST change derived from years $1-20$ and $21-150$ of these same abrupt $4 \mathrm{xCO}_{2}$ experiments, respectively; Table 2) suggests this is predominantly the result of a weakening of the negative lapse rate feedback, which is at least partly due to a shift in the warming pattern away from the west Pacific ascent region to the east Pacific with time.
When AOGCMs are forced with an abrupt quadrupling of $\mathrm{CO}_{2}$, they generally show a change in feedback strength-effective climate sensitivity increases-on multidecadal time scales. The change in feedback strength in HadGEM2 is close to that of the CMIP5 multimodel-mean change (Andrews et al. 2015); thus HadGEM2 is not unusual in this respect. This gives us confidence that the mechanism we describe may be typical of CMIP5 model responses. Yet an outstanding question is why do some AOGCMs show larger changes in feedback strengths than others? One possible explanation is that some models simply have atmospheric feedbacks that are more sensitive to changes in SST patterns than other models. This is likely given that differences in atmospheric physics and parameterizations give rise to a wide range of feedbacks strengths across models when forced with identical SST patterns (e.g., Ringer et al. 2014), so a diverse response to the same change in SST pattern is to be expected. The experiments used here (amip-fast $4 \mathrm{k}$, amip-slow4K, and amip-obs4K) have been put forward for inclusion in CFMIP3 (alongside amip-p4k and amip-future4k) (Webb et al. 2017) for a multimodel comparison to help quantify this dependence and assess its robustness.

Alternatively, some models may have less constant feedback strengths in abrupt $4 \mathrm{xCO}_{2}$ than other models because different AOGCMs simulate different changes in warming patterns. We investigate this in Fig. 6, which shows the evolution of the east-west tropical Pacific warming index in CMIP5 abrupt $4 \mathrm{xCO}_{2}$ simulations for the same set of models studied by Andrews et al. (2015). The index is generally near zero or negative for years 1-20 (Fig. 6a), indicating that most models tend to simulate a delayed or similar level of warming in the southeast tropical Pacific compared to the west. Subsequently, for years $21-150$, the index is robustly positive (Fig. 6a), showing that virtually all models simulate a greater southeast tropical Pacific warming relative to the west Pacific on longer time scales, both in absolute terms (Fig. 6a) and relative to the first 20 years (Fig. 6b). This is consistent with the mechanism proposed here and the robust increase in cloud feedback found across CMIP5 models during these time periods. However, the variation in this index is unable to explain the variation in the change in CMIP5 feedback strengths found in Andrews et al. (2015). For example, nearly all models show a cloud feedback that becomes less negative (or more positive) with time, but the variation in this change [defined in Andrews et al. (2015) as the change in feedback over years 21-150 relative to years 1-20] across CMIP5 models does not significantly correlate with the change in east-west Pacific warming index of 
(a) Years 1-20 Years 21-150

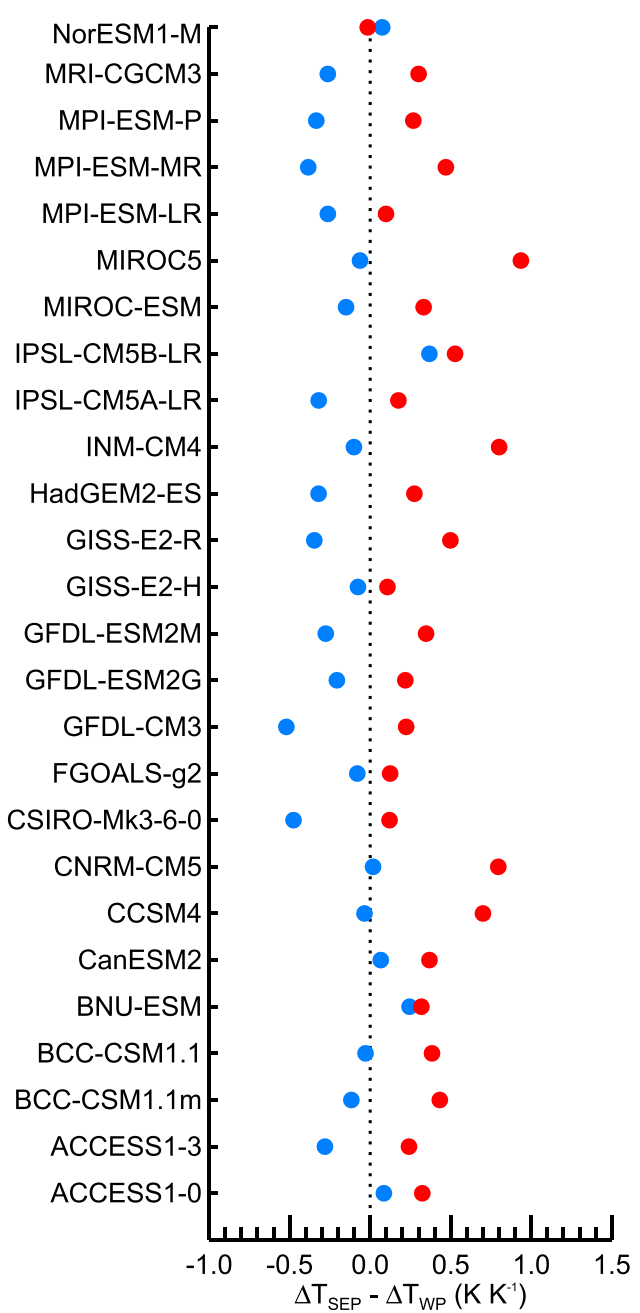

(b) Change in index

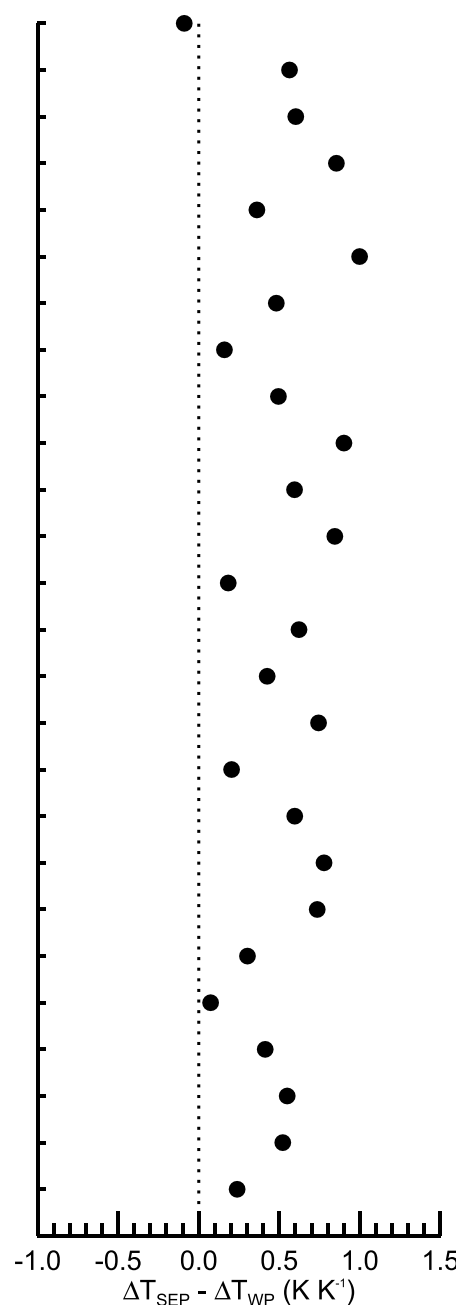

FIG. 6. The tropical Pacific warming pattern index [i.e., the difference between the southeast tropical Pacific $\Delta T_{\mathrm{SEP}}$ and west Pacific temperature change $\Delta T_{\mathrm{WP}}$ per unit globalmean surface air temperature change (calculated from the slope of the linear regression of annual-mean $\Delta T_{\mathrm{SEP}}-\Delta T_{\mathrm{WP}}$ against global annual-mean surface air temperature change)] in CMIP5 AOGCM experiments forced by an abrupt quadrupling of $\mathrm{CO}_{2}$, for (a) the fast (years 1-20; blue) and slow (years 21-150; red) responses. (b) The change in tropical Pacific warming index, calculated as the slow minus fast response.

Fig. $6 \mathrm{~b}(r=0.2)$. This could in part be because the index is not refined well enough to capture key regional warming contrasts of individual AOGCMs. Another explanation is that changes in the warming pattern in other regions, such as at high latitudes or in the Southern Ocean, could be a significant driver of the change in global feedback strengths, but this effect will not be captured by our index since our focus has been on the tropical Pacific. Alternatively, the lack of correlation could simply suggest that the effect of uncertainty in the pattern of SST change across models on the change in feedback strength is small compared to the differences that arise as a result of the different atmospheric physics and parameterizations across the models, as discussed above. Future model intercomparisons will address these issues.

We have focused on the patterns of SST change in the tropical Pacific as a key driver of climate feedback variation. However, other regions could also be important. For example, changes in the warming pattern at high latitudes (e.g., Armour et al. 2013; Rose et al. 2014; Kang and Xie 2014) and in the Southern Ocean (e.g., Senior and Mitchell 2000) have also been shown to change feedback strengths. There would be value in future 
targeted experiments analogous to the ones presented here-including regional patch experiments (e.g., Zhou et al. 2017)—but focusing on prescribed patterns of SST change associated modes of climate variability (such as ENSO and the PDO) and different aspects of the forced response, including the role of spatiotemporal variations in the warming patterns of the Southern Ocean and at high latitudes.

Recent decades have shown global temperature increases with a lack of warming (or even cooling) in the eastern Pacific while warming in the western Pacific (e.g., Hartmann et al. 2013; Dai et al. 2015). Assuming this pattern is the result of unforced climate variability (e.g., Kosaka and Xie 2013; Dai et al. 2015; Newman et al. 2016), or even in part the result of temporal and spatial variations in anthropogenic aerosol forcing (e.g., Boo et al. 2015; Smith et al. 2015), rather than the long-term response to greenhouse gas forcing, then we do not expect it to continue into the long-term future. This is because the eventual enhanced warming in the eastern Pacific, Southern Ocean, high latitudes, and land regions projected by AOGCMs when forced with long-term greenhouse gas increases is consistent with physical understanding (Collins et al. 2013), regardless of whether AOGCMs struggle to simulate recent decadal trends in SST patterns (Zhou et al. 2016; Mauritsen 2016). Hence, from the physical understanding developed here, we suggest that once this pattern of long-term SST change fully emerges in the future, then radiative feedbacksparticularly from cloud and lapse rate feedbacks-will become less negative and effective climate sensitivity will rise.

Acknowledgments. We thank Jonathan Gregory for many useful discussions on inconstant feedbacks, Adam Scaife for discussions on dynamical responses, and Brian Soden for supplying the radiative kernels. We are very grateful to the editor, Kyle Armour, and two anonymous reviewers for constructive comments on the manuscript. This work was supported by the Joint U.K. BEIS/Defra Met Office Hadley Centre Climate Programme (GA01101). We acknowledge the World Climate Research Programme's Working Group on Coupled Modelling, which is responsible for CMIP, and we thank the climate modeling groups (listed in Fig. 6 of this paper) for producing and making available their model output. For CMIP, the U.S. Department of Energy's Program for Climate Model Diagnosis and Intercomparison provides coordinating support and led development of software infrastructure in partnership with the Global Organization for Earth System Science Portals.

\section{REFERENCES}

Allan, R. P., C. Liu, N. G. Loeb, M. D. Palmer, M. Roberts, D. Smith, and P.-L. Vidale, 2014: Changes in global net radiative imbalance 1985-2012. Geophys. Res. Lett., 41, 55885597, https://doi.org/10.1002/2014GL060962.

Andrews, T., 2014: Using an AGCM to diagnose historical effective radiative forcing and mechanisms of recent decadal climate change. J. Climate, 27, 1193-1209, https://doi.org/ 10.1175/JCLI-D-13-00336.1.

— J. M. Gregory, M. J. Webb, and K. E. Taylor, 2012a: Forcing, feedbacks and climate sensitivity in CMIP5 coupled atmosphere-ocean climate models. Geophys. Res. Lett., 39, L09712, https://doi.org/10.1029/2012GL051607.

_ M. A. Ringer, M. Doutriaux-Boucher, and M. J. Webb, 2012b: Sensitivity of an Earth system climate model to idealized radiative forcing. Geophys. Res. Lett., 39, L10702, https:// doi.org/10.1029/2012GL051942.

— J. M. Gregory, and M. J. Webb, 2015: The dependence of radiative forcing and feedback on evolving patterns of surface temperature change in climate models. J. Climate, 28, 16301648, https://doi.org/10.1175/JCLI-D-14-00545.1.

Armour, K. C., 2016: Projection and prediction: Climate sensitivity on the rise. Nat. Climate Change, 6, 896-897, https://doi.org/ 10.1038/nclimate3079.

_ 2017: Energy budget constraints on climate sensitivity in light of inconstant climate feedbacks. Nat. Climate Change, 7, 331335, https://doi.org/10.1038/nclimate3278.

_ C. M. Bitz, and G. H. Roe, 2013: Time-varying climate sensitivity from regional feedbacks. J. Climate, 26, 4518-4534, https://doi.org/10.1175/JCLI-D-12-00544.1.

_ , J. Marshall, J. R. Scott, A. Donohoe, and E. R. Newsom, 2016: Southern Ocean warming delayed by circumpolar upwelling and equatorward transport. Nat. Geosci., 9, 549-554, https://doi.org/10.1038/ngeo2731.

Bony, S., and Coauthors, 2006: How well do we understand and evaluate climate change feedback processes? J. Climate, $\mathbf{1 9}$, 3445-3482, https://doi.org/10.1175/JCLI3819.1.

_ M. Webb, C. Bretherton, S. Klein, P. Siebesma, G. Tselioudis, and M. Zhang, 2011: CFMIP: Towards a better evaluation and understanding of clouds and cloud feedbacks in CMIP5 models. CLIVAR Exchanges, No. 56, International CLIVAR Project Office, Southampton, United Kingdom, 20-24.

Boo, K.-O., B. B. B. Booth, Y.-H. Byun, J. Lee, C. Cho, S. Shim, and K.-T. Kim, 2015: Influence of aerosols in multidecadal SST variability simulations over the North Pacific. J. Geophys. Res. Atmos., 120, 517-531, https://doi.org/10.1002/ 2014JD021933.

Booth, B. B. B., N. J. Dunstone, P. R. Halloran, T. Andrews, and N. Bellouin, 2012: Aerosols implicated as a prime driver of twentieth-century North Atlantic climate variability. Nature, 484, 228-232, https://doi.org/10.1038/ nature 10946.

Bretherton, C., 2015: Insights into low-latitude cloud feedbacks from high-resolution climate models. Philos. Trans. Roy. Soc. London, 373A, 20140415, https://doi.org/10.1098/rsta.2014.0415.

Brient, F., T. Schneider, Z. Tan, S. Bony, X. Qu, and A. Hall, 2016 : Shallowness of tropical low clouds as a predictor of climate models' response to warming. Climate Dyn., 47, 433-449, https://doi.org/10.1007/s00382-015-2846-0.

Cess, R. D., and Coauthors, 1996: Cloud feedback in atmospheric general circulation models: An update. J. Geophys. Res., 101, 12 791-12 794, https://doi.org/10.1029/96JD00822. 
Collins, M., and Coauthors, 2013: Long-term climate change: Projections, commitments and irreversibility. Climate Change 2013: The Physical Science Basis, T. F. Stocker et al., Eds., Cambridge University Press, 1029-1136.

Dai, A., J. C. Fyfe, S.-P. Xie, and X. Dai, 2015: Decadal modulation of global surface temperature by internal climate variability. Nat. Climate Change, 5, 555-559, https://doi.org/10.1038/ nclimate2605.

Dessler, A. E., 2013: Observations of climate feedbacks over 2000 10 and comparisons to climate models. J. Climate, 26, 333-342, https://doi.org/10.1175/JCLI-D-11-00640.1.

Feldl, N., and G. H. Roe, 2013: The nonlinear and nonlocal nature of climate feedbacks. J. Climate, 26, 8289-8304, https://doi.org/ 10.1175/JCLI-D-12-00631.1.

Ferraro, A., F. Lambert, M. Collins, and G. Miles, 2015: Physical mechanisms of tropical climate feedbacks investigated using temperature and moisture trends. J. Climate, 28, 8968-8987, https://doi.org/10.1175/JCLI-D-15-0253.1.

Flannaghan, T. J., S. Fueglistaler, I. M. Held, S. Po-Chedley, B. Wyman, and M. Zhao, 2014: Tropical temperature trends in atmospheric general circulation model simulations and the impact of uncertainties in observed SSTs. J. Geophys. Res. Atmos., 119, 13327-13 337, https://doi.org/10.1002/ 2014JD022365.

Flato, G., and Coauthors, 2013: Evaluations of climate models. Climate Change 2013: The Physical Science Basis, T. F. Stocker et al., Eds., Cambridge University Press, 741-866.

Forster, P. M., 2016: Inference of climate sensitivity from analysis of Earth's energy budget. Annu. Rev. Earth Planet. Sci., 44, 85106, https://doi.org/10.1146/annurev-earth-060614-105156.

—, T. Andrews, P. Good, J. M. Gregory, L. S. Jackson, and M. Zelinka, 2013: Evaluating adjusted forcing and model spread for historical and future scenarios in the CMIP5 generation of climate models. J. Geophys. Res. Atmos., 118, 11391150, https://doi.org/10.1002/jgrd.50174.

Geoffroy, O., D. Saint-Martin, G. Bellon, A. Voldoire, D. J. L. Olivié, and S. Tytéca, 2013: Transient climate response in a two-layer energy-balance model. Part II: Representation of the efficacy of deep-ocean heat uptake and validation for CMIP5 AOGCMs. J. Climate, 26, 1859-1876, https://doi.org/ 10.1175/JCLI-D-12-00196.1.

Gill, A. E., 1980: Some simple solutions for heat-induced tropical circulation. Quart. J. Roy. Meteor. Soc., 106, 447-462, https:// doi.org/10.1002/qj.49710644905.

Gregory, J. M., and T. Andrews, 2016: Variation in climate sensitivity and feedback parameters during the historical period. Geophys. Res. Lett., 43, 3911-3920, https://doi.org/10.1002/ 2016 GL068406.

Hartmann, D. L., and Coauthors, 2013: Observations: Atmosphere and surface. Climate Change 2013: The Physical Science Basis, T. F. Stocker et al., Eds., Cambridge University Press, 159254.

Held, I. M., and Coauthors, 2010: Probing the fast and slow components of global warming by returning abruptly to preindustrial forcing. J. Climate, 23, 2418-2427, https://doi.org/ 10.1175/2009JCLI3466.1.

Hurrell, J., J. Hack, D. Shea, J. Caron, and J. Rosinski, 2008: A new sea surface temperature and sea ice boundary dataset for the Community Atmosphere Model. J. Climate, 21, 5145-5153, https://doi.org/10.1175/2008JCLI2292.1.

Kang, S. M., and S. Xie, 2014: Dependence of climate response on meridional structure of external thermal forcing. J. Climate, 27, 5593-5600, https://doi.org/10.1175/JCLI-D-13-00622.1.
Klein, S. A., and D. L. Hartmann, 1993: The seasonal cycle of low stratiform clouds. J. Climate, 6, 1587-1606, https://doi.org/ 10.1175/1520-0442(1993)006<1587:TSCOLS $>2.0$. CO;2.

Kosaka, Y., and S.-P. Xie, 2013: Recent global-warming hiatus tied to equatorial Pacific surface cooling. Nature, 501, 403-407, https://doi.org/10.1038/nature12534.

Lambert, F. H., and P. C. Taylor, 2014: Regional variation of the tropical water vapor and lapse rate feedbacks. Geophys. Res. Lett., 41, 7634-7641, https://doi.org/10.1002/2014GL061987.

Li, C., J.-S. V. Storch, and J. Marotzke, 2013: Deep-ocean heat uptake and equilibrium climate response. Climate Dyn., 40, 1071-1086, https://doi.org/10.1007/s00382-012-1350-z.

Luo, Y., J. Lu, F. Liu, and O. Garuba, 2017: The role of ocean dynamical thermostat in delaying the El Niño-like response over the equatorial Pacific to climate warming. J. Climate, $\mathbf{3 0}$, 2811-2827, https://doi.org/10.1175/JCLI-D-16-0454.1.

Martin, G. M., and Coauthors, 2011: The HadGEM2 family of Met Office Unified Model climate configurations. Geosci. Model Dev., 4, 723-757, https://doi.org/10.5194/gmd-4-723-2011.

Mauritsen, T., 2016: Global warming: Clouds cooled the Earth. Nat. Geosci., 9, 865-867, https://doi.org/10.1038/ngeo2838.

Newman, M., and Coauthors, 2016: The Pacific decadal oscillation, revisited. J. Climate, 29, 4399-4427, https://doi.org/10.1175/ JCLI-D-15-0508.1.

Po-Chedley, S., and Q. Fu, 2012: Discrepancies in tropical upper tropospheric warming between atmospheric circulation models and satellites. Environ. Res. Lett., 7, 044018, https:// doi.org/10.1088/1748-9326/7/4/044018.

Qu, X., A. Hall, S. A. Klein, and P. M. Cadwell, 2014: On the spread of changes in marine low cloud cover in climate model simulations of the 21st century. Climate Dyn., 42, 2603-2626, https://doi.org/10.1007/s00382-013-1945-z.

$\ldots, \ldots, \ldots$, and $\_$2015a: The strength of the tropical inversion and its response to climate change in 18 CMIP5 models. Climate Dyn., 45, 375-396, https://doi.org/10.1007/ s00382-014-2441-9.

,$--\longrightarrow$, and A. M. DeAngelis, 2015b: Positive tropical marine low-cloud cover feedback inferred from cloudcontrolling factors. Geophys. Res. Lett., 42, 7767-7775, https://doi.org/10.1002/2015GL065627.

Rieck, M., L. Nuijens, and B. Stevens, 2012: Marine boundary layer cloud feedbacks in a constant relative humidity atmosphere. J. Atmos. Sci., 69, 2538-2550, https://doi.org/10.1175/ JAS-D-11-0203.1.

Ringer, M. A., T. Andrews, and M. J. Webb, 2014: Global-mean radiative feedbacks and forcing in atmosphere-only and coupled atmosphere-ocean climate change experiments. Geophys. Res. Lett., 41, 4035-4042, https://doi.org/10.1002/2014GL060347.

Rose, B. E. J., K. C. Armour, D. S. Battisti, N. Feldl, and D. D. B. Koll, 2014: The dependence of transient climate sensitivity and radiative feedbacks on the spatial pattern of ocean heat uptake. Geophys. Res. Lett., 41, 1071-1078, https://doi.org/ 10.1002/2013GL058955.

Rugenstein, M. A. A., K. Caldeira, and R. Knutti, 2016: Dependence of global radiative feedbacks on evolving patterns of surface heat fluxes. Geophys. Res. Lett., 43, 9877-9885, https:// doi.org/10.1002/2016GL070907.

Scaife, A. A., and Coauthors, 2016: Tropical rainfall, Rossby waves and regional winter climate predictions. Quart. J. Roy. Meteor. Soc., 143, 1-11, https://doi.org/10.1002/qj.2910.

Senior, C. A., and J. F. B. Mitchell, 2000: The time-dependence of climate sensitivity. Geophys. Res. Lett., 27, 2685-2688, https:// doi.org/10.1029/2000GL011373. 
Smith, D. M., and Coauthors, 2015: Earth's energy imbalance since 1960 in observations and CMIP5 models. Geophys. Res. Lett., 42, 1205-1213, https://doi.org/10.1002/2014GL062669.

Soden, B., and I. Held, 2006: An assessment of climate feedbacks in coupled ocean-atmosphere models. J. Climate, 19, 3354-3360, https://doi.org/10.1175/JCLI3799.1.

,,,- R. Colman, K. M. Shell, J. T. Kiehl, and C. A. Shields, 2008: Quantifying climate feedbacks using radiative kernels. J. Climate, 21, 3504-3520, https://doi.org/10.1175/2007JCLI2110.1.

Taylor, K. E., D. Williamson, and F. Zwiers, 2000: The sea surface temperature and sea-ice concentration boundary conditions for AMIP II simulations. PCMDI Rep. 60, 28 pp.

$\longrightarrow$, R. J. Stouffer, and G. A. Meehl, 2012: An overview of CMIP5 and the experiment design. Bull. Amer. Meteor. Soc., 93, 485498, https://doi.org/10.1175/BAMS-D-11-00094.1.

Vial, J., J.-L. Dufresne, and S. Bony, 2013: On the interpretation of inter-model spread in CMIP5 climate sensitivity estimates. Climate Dyn., 41, 3339-3362, https://doi.org/10.1007/ s00382-013-1725-9.

Webb, M. J., and A. P. Lock, 2013: Coupling between subtropical cloud feedback and the local hydrological cycle in a climate model. Climate Dyn., 41, 1923-1939, https://doi.org/10.1007/ s00382-012-1608-5.

, F. H. Lambert, and J. M. Gregory, 2013: Origins of differences in climate sensitivity, forcing and feedback in climate models. Climate Dyn., 40, 677-707, https://doi.org/10.1007/ s00382-012-1336-x.

_ , and Coauthors, 2017: The Cloud Feedback Model Intercomparison Project (CFMIP) contribution to CMIP6. Geosci. Model Dev., 10, 359-384, https://doi.org/10.5194/ gmd-10-359-2017.

Williams, K. D., W. J. Ingram, and J. M. Gregory, 2008: Time variation of effective climate sensitivity in GCMs. J. Climate, 21, 5076-5090, https://doi.org/10.1175/2008JCLI2371.1.

Wood, R., and C. S. Bretherton, 2006: On the relationship between stratiform low cloud cover and lower-tropospheric stability. J. Climate, 19, 6425-6432, https://doi.org/10.1175/ JCLI3988.1.

Zhou, C., M. D. Zelinka, A. E. Dessler, and S. A. Klein, 2015: The relationship between interannual and long-term cloud feedbacks. Geophys. Res. Lett., 42, $10463-10469$, https://doi.org/ 10.1002/2015GL066698.

,-- , and S. A. Klein, 2016: Impact of decadal cloud variations on the Earth's energy budget. Nat. Geosci., 9, 871-874, https://doi.org/10.1038/ngeo2828.

,$- \ldots$, and — 2017: Analyzing the dependence of global cloud feedback on the spatial pattern of sea surface temperature change with a Green's function approach. $J . A d v$. Model. Earth Syst., 9, 2174-2189, https://doi.org/10.1002/ 2017MS001096. 